\title{
Reference values of 25-hydroxyvitamin D revisited: a position statement from the Brazilian Society of Endocrinology and Metabolism (SBEM) and the Brazilian Society of Clinical Pathology/Laboratory Medicine (SBPC)
}

DOI: $10.20945 / 2359-3997000000258$

Arch Endocrinol Metab. 2020;64(4):462-78

Where you read (TITLE):

Reference values of 25-hydroxyvitamin D revisited: a position statement from the Brazilian Society of Endocrinology and Metabolism (SBEM) and the Brazilian Society of Clinical Pathology/Laboratory Medicine (SBPC)

Should read:

Reference values of 25-hydroxyvitamin D revisited: a position statement from the Brazilian Society of Endocrinology and Metabolism (SBEM) and the Brazilian Society of Clinical Pathology/Laboratory Medicine (SBPC/ML)

Where you read (TEXT):

These assays include a first step in which $25(\mathrm{OH}) \mathrm{D}$ is dissociated from its carrier proteins. In a second step, the $25(\mathrm{OH}) \mathrm{D}$ in the sample competes with an analogue for the same sites of the ligand's assay [anti-25(OH)D or DBP antibodies].

Should read:

These assays include a first step in which $25(\mathrm{OH}) \mathrm{D}$ is dissociated from its carrier proteins. In a second step, the 25(OH)D in the sample competes with an analogue for the same sites of the ligand's assay [anti-25(OH)D antibodies and DBP].

Where you read:

Table 2. Clinical conditions and groups that benefit from 25-hydroxyvitamin (25[OH]D) concentrations above $30 \mathrm{ng} / \mathrm{mL}$

\begin{tabular}{ll}
\hline Groups & Clinical Conditions \\
\hline Elderly (> 65 years) & Osteoporosis (primary or secondary) \\
Pregnant women & Fractures due to fragility \\
& Metabolic bone diseases (osteomalacia, \\
& osteogenesis imperfecta, primary \\
& hyperparathyroidism) \\
& Secondary hyperparathyroidism \\
& Sarcopenia \\
& Recurring falls \\
& Chronic renal disease \\
& Malabsorption syndrome \\
& Liver failure \\
& Anorexia nervosa \\
& Cancer \\
\hline
\end{tabular}

Should read:

Table 2. Clinical conditions and groups that benefit from 25-hydroxyvitamin (25[OH]D) concentrations above $30 \mathrm{ng} / \mathrm{mL}$

\begin{tabular}{ll}
\hline Groups & Clinical Conditions \\
\hline Elderly (> 65 years) & Osteoporosis (primary or secondary) \\
Pregnant women & Fractures due to fragility \\
& Metabolic bone diseases (osteomalacia, \\
& osteogenesis imperfecta, primary \\
& hyperparathyroidism) \\
& Secondary hyperparathyroidism \\
& Sarcopenia \\
& Recurring falls \\
& Chronic renal disease \\
& Malabsorption syndrome \\
& Liver failure \\
& Diabetes mellitus type 1 \\
& Cancer \\
\hline
\end{tabular}

Where you read:

Correspondence to:

Carolina Moreira

Rua Leão Júnior, 285

80060-000 - Curitiba, PR Brasil

carolina.aguiar.moreira@gmail.com

Should read

Carolina Moreira

Av Agostinho Leão Júnior, 285

80060-000 - Curitiba, PR Brasil

carolina.aguiar.moreira@gmail.com 